\title{
Outcome of popliteal arterial injuries presenting to the Teaching Hospital, Anuradhapura
}

\author{
Sriharan Parathan, Joel Arudchelvam, Amanthana Marasinghe \\ Teaching Hospital, Anuradhapura
}

Keywords: Popliteal arterial injury; popliteal venous injury; outcome; fracture; amputation

\section{Abstract \\ Introduction \\ Popliteal artery (PA) injury is an emergency that has a high limb threat potential.}

\section{Methodology}

This is a retrospective study of those with documented PA injuries in bed head tickets among those presenting with arterial injuries to the Teaching Hospital, Anuradhapura (THA) from January 2017 to June 2019. Demography, anatomical details of injury, concomitant injuries, type of surgical intervention and perioperative outcomes were assessed.

\section{Results}

Twenty case records were studied. Eighteen (90\%) were males, with a mean age of 38.7 years (18-69). Eight (40\%) were following motorcycle accidents and 7 (35\%) were trap gun injuries. Median ischemic time was 9.5 hours (3-29). Seventeen $(85 \%)$ had associated fracture or dislocation (p0.003). Four (20\%) had associated venous injury. Seven arteries (35\%) were contused, 6 (30\%) were lacerated. Eleven $(55 \%)$ underwent reversed saphenous vein graft repair, end to end anastomosis was done in $1(5 \%)$ and ligation was done in $2(10 \%)$. None of the patients underwent fasciotomy at the hospital where they were admitted first. Nine of fourteen patients $(64.3 \%)$ had all compartments viable on fasciotomy. Two (10\%) patients following trap gun injury who also had associated venous injury underwent amputation. Concomitant venous injury had a significant association with amputation rate ( $\mathrm{p} 0.0316)$

\section{Conclusion}

Motorcycle accidents and trap guns were the leading cause of PA injury. PA injury was significantly associated with fractures around the knee joint. Concomitant popliteal venous

\footnotetext{
Correspondence: Joel Arudchelvam

E-mail: joelaru@yahoo.com

Received: 05-10-2019 Accepted: 30-12-2019

(iD) https://orcid.org/0000-0002-4371-4527

DOI: http://doi.org/10.4038/sljs.v37i4.8642
}

injury, which is common after trap gun injury, had significant association with poor outcome.

\section{Introduction}

Popliteal arterial injury is a potentially life or limb threatening vascular emergency. The close anatomic relationship of the popliteal artery to the distal femur, proximal tibia and knee joint apparatus makes it extremely vulnerable to injury in the case of skeletal and joint injuries in the knee region. Popliteal arterial injury is commonly associated with fractures of the tibial plateau, supracondylar femur fractures and knee joint dislocations from road traffic accidents.

Trap gun injuries are also common in rural Anuradhapura and adjacent districts. There are approximately 200 admissions annually to Teaching Hospital, Anuradhapura following trap gun injuries which is one of the leading causes of popliteal arterial injury with associated musculoskeletal trauma (1).

Paucity of Sri Lankan literature is noted regarding civilian popliteal arterial injuries. Available studies regarding popliteal arterial injury describe mainly the war time experiences. The aim of this study is to describe the injury pattern, associated factors, treatment and perioperative outcome of popliteal arterial injuries presenting to THA.

\section{Methodology}

This was a retrospective study from available hospital records of those treated for PA injury at the Teaching Hospital, Anuradhapura from 01st January 2017 to 31st June 2019. Patients with arterial injuries, but poor documentation were excluded from this study.

Patient demographics, mechanism of injury, arterial level of injury, associated fractures or dislocation, muscle viability, definitive vascular surgical intervention, ischaemic time, orthopaedic intervention and outcome were included as study variables.

The data analysis was done using SPSS v.21. Categorical data was analysed using Fisher Exact Test and one sample Binominal test. A ' $p$ ' value of less than 0.05 was taken as statistically significant. 


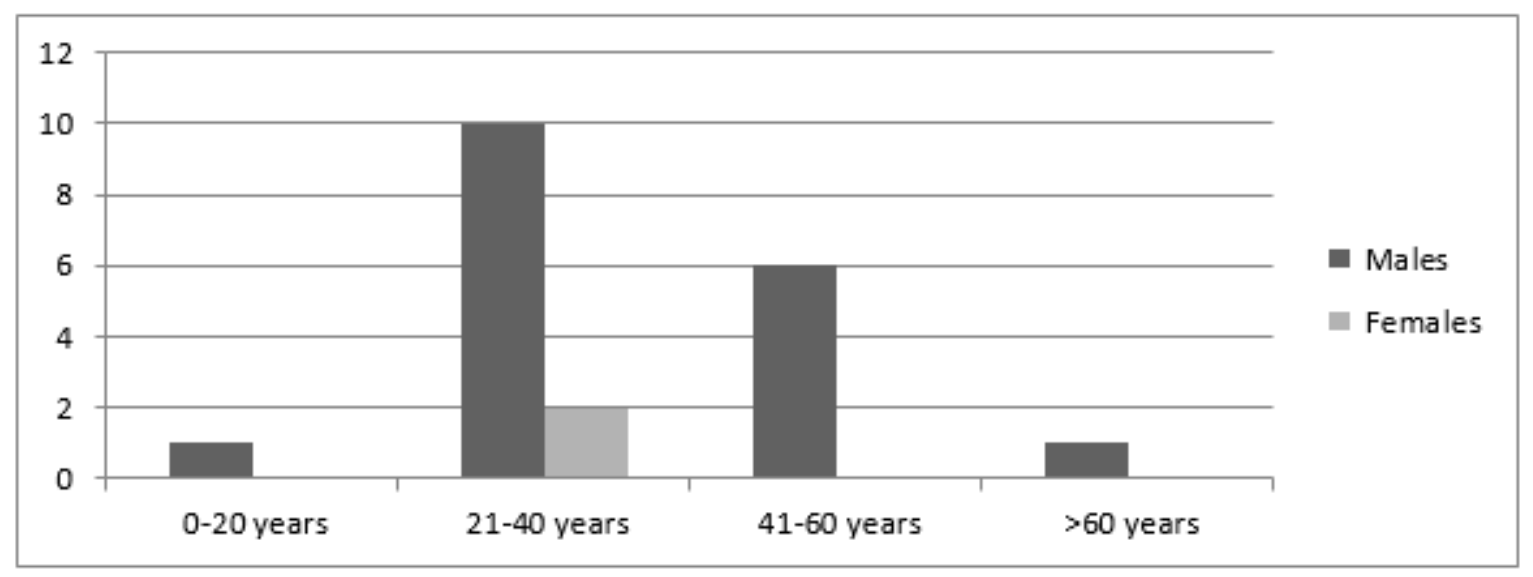

Graph 1. Age and gender of study population

\section{Results}

Twenty patients with case records were studied. Eighteen (90\%) were males ( $\mathrm{p} 0.000$ ). Mean age was 38.7 years (Range 18-69). Eighteen (90\%) patients were in the 21-60 year age group (Graph 1).

All had been transferred from another hospital. Mean distance of transfer was $102 \mathrm{~km}$ (Range 28-195). Distance between THA and other hospitals was less than $50 \mathrm{~km}$ in only $6(30 \%)$, from $51 \mathrm{~km}$ to $100 \mathrm{~km}$ in $4(20 \%)$, from $101 \mathrm{~km}$ to $150 \mathrm{~km}$ in $8(40 \%)$ and more than $150 \mathrm{~km}$ in $2(10 \%)$. Median ischaemic time was 9.5 hours (Range 3-29)

Eleven $(55 \%)$ of PA injuries were following road traffic accidents. Eight (40\%) were in motorcyclists and one was a pedestrian. Of the remaining 9 , seven $(35 \%)$ were from trap guns and two $(10 \%)$ were iatrogenic during orthopaedic internal fixations. PA injuries were significantly associated with fractures ( $p$ 0.003) Details of the type of skeletal and joint injuries associated with PA injuries is depicted in table 1 .

Spanning external fixation was done in $13 / 17$ (76.5\%) prior to vascular repair. $2 / 17(11.8 \%)$ had internal fixation of tibial

Table 1. Associated skeletal injuries

\begin{tabular}{|l|c|c|c|}
\hline Fracture / Dislocation & $\begin{array}{l}\text { Open } \\
\text { fractures }\end{array}$ & $\begin{array}{l}\text { Closed } \\
\text { fractures }\end{array}$ & $\begin{array}{c}\text { Number } \\
\text { of cases }\end{array}$ \\
\hline Tibial plateu fracture & 0 & 7 & 7 \\
\hline $\begin{array}{l}\text { Tibial plateu fracture with } \\
\text { knee joint dislocation }\end{array}$ & 1 & 1 & 2 \\
\hline $\begin{array}{l}\text { Tibial plateu fracture with } \\
\text { supracondylar }\end{array}$ & 0 & 1 & 1 \\
\hline femur fracture & 0 & 1 & 1 \\
\hline $\begin{array}{l}\text { Supracondylar femur } \\
\text { fracture }\end{array}$ & 0 & 2 & 2 \\
\hline $\begin{array}{l}\text { Extra-articular proximal } \\
\text { tibial fracture }\end{array}$ & 1 & 0 & 1 \\
\hline $\begin{array}{l}\text { Extra-articular proximal } \\
\text { tibial fracture }\end{array}$ & 2 & 1 & 3 \\
\hline
\end{tabular}

plateau fracture during which procedure iatrogenic injury of popliteal artery occurred. Plaster of Paris back slab immobilization was done in 2/17 (11.8\%) who had fibular head fracture.

PA injury was associated with popliteal vein injury in 4 (20\%) and common peroneal nerve injury in $1(5 \%)$. Concomitant popliteal venous injury, $3 / 7$ were more commonly seen following trap gun injuries ( $\mathrm{p}=0.1011)$. Traffic accidents had a significant association with PA contusions $(p=0.04)$ while trap guns caused significantly more arterial lacerations $(\mathrm{p}=0.04)$.

Reversed saphenous venous graft repair was done in 11 (55\%) patients. Five (25\%) underwent thrombectomy only. End to end anastomosis was done in $1(5 \%)$ patient. Venous patch repair was done in $1(5 \%)$ patient. Ligation was done in 2 $(10 \%)$ patients who had concomitant popliteal artery and vein injury following trap gun injury.

None had a fasciotomy prior to transfer to THA. Fourteen patients were subjected to fasciotomy at THA prior to vascular repair. Nine $(64.3 \%)$ had all 4 compartments viable with a mean ischaemic time of 8.5 hours. One $(7.1 \%)$ had three compartments viable with 17 hours of ischaemia. Another (7.1\%) had two compartments viable after 13 hours of ischaemia and one $(7.1 \%)$ had only one viable compartment with 7 hours of ischemia. All the compartments were nonviable with a mean ischemic time of 9.5 hours in $2 / 14(14.2 \%)$ who also had concomitant popliteal vein injury and both were from trap gun injuries.

Table 2. Arterial level injury

\begin{tabular}{|l|c|c|c|}
\hline Arterial level injury & $\begin{array}{c}\text { Trap gun } \\
\text { injury }\end{array}$ & RTA & No of cases \\
\hline Documented & & & 15 \\
\hline Contusion & 1 & 6 & $7(46.7 \%)$ \\
\hline Laceration & 5 & 1 & $6(40 \%)$ \\
\hline Spasm & 1 & 1 & $2(13.3 \%)$ \\
\hline $\begin{array}{l}\text { Not assessed due to } \\
\text { fibrosed popliteal fossa }\end{array}$ & & & 2 \\
\hline
\end{tabular}

The Sri Lanka Journal of Surgery 2019; 37(4): 14-17 
Only those two were subjected to primary amputation. Details of the type of arterial injury, concomitant injuries, ischaemia time, compartment viability, revascularization and early outcomes are depicted in table 3.

\section{Discussion}

The data presented shows that young males (mean age - 38.7 years), particularly motorcyclists $(40 \%)$ are at risk of PA injury. Such injuries are likely to have a major economic impact on young families. Similar data has been reported in other regional and international studies on injuries to PAs (1, $2,3,4)$. Preventive measures targeting vulnerable motorcyclist needs emphasis. Trap gun injuries are still a major cause $(35 \%)$ and a continuing concern in rural Sri Lanka. THA has attributed approximately 200 admissions annually to injuries from trap guns (5). The only two primary amputations were following trap gun accidents and must have been due to the extent of soft tissue injuries, contamination and associated popliteal venous injuries. Implementation and enforcement of the existing legal framework against trap gun users is mandatory to prevent trap gun injuries and associated morbidity and mortality.

The known association between PA injury and fracturedislocations around the knee was confirmed in this small study. However, our patients with PA injuries had more closed injuries as opposed to most other series that have reported open injuries $(1,2,3,4,6)$. Interestingly, the poor outcomes reported when PA injuries were associated with fracture dislocations (10) were not seen our series.

In our study population $4(20 \%)$ had concomitant PA and vein injury. Two of these patients presented with dead muscle in all four compartments and underwent primary amputation. Another with concomitant venous injury had three nonviable muscle compartments after only 7 hours from injury pointing to the understandably adverse influence on muscle viability. Primary amputation had a significant association with concomitant PA and vein injury $(\mathrm{p}=0.0316)$ in our series and is in keeping with results reported elsewhere (7).

Table 3. Summary of Outcome (No - number, Sex - Male, F - Female, RTA - Road Traffic Accidents, PA - Popliteal Artery, PV Popliteal Vein, NV - Non Viable, ND - Not Documented, IT - Ischemic Time, RSVG - Reversed Saphenous Vein Graft, EE - End To End Repair, LR - Lateral Repair, TG - Trap Gun, IJ - Iatrogenic Injury, Comp - Compartment Viability, AV - All Compartments Viable, T-Thrombctomy, VP - Venous Patch)

\begin{tabular}{|c|c|c|c|c|c|c|c|c|}
\hline No & Age & Sex & Mechanism & Vessel & IT & Comp & Surgery & outcome \\
\hline 1 & 37 & $\mathrm{M}$ & RTA & $\overline{P A}+\mathrm{PV}$ & 7.0 & $3 \mathrm{NV}$ & RSVG, VEIN - LR & Healing \& salvaged \\
\hline 2 & 69 & $\mathrm{M}$ & RTA & $\mathrm{PA}$ & 13.0 & AV & RSVG & Healing \& salvaged \\
\hline 3 & 60 & $\mathrm{M}$ & RTA & PA & 29.0 & $\mathrm{ND}$ & RSVG & Healing \& salvaged \\
\hline 4 & 37 & $\mathrm{M}$ & TG & PA & 6.0 & AV & RSVGR & Healing \& salvaged \\
\hline 5 & 35 & $\mathrm{M}$ & TG & $\mathrm{PA}+\mathrm{PV}$ & 5.0 & AV & $T+$ VEIN LR & Healing \& salvaged \\
\hline 6 & 37 & $\mathrm{M}$ & TG & $\mathrm{PA}$ & 8.0 & AV & RSVG & Healing \& salvaged \\
\hline 7 & 41 & $\mathrm{M}$ & TG & $\mathrm{PA}+\mathrm{PV}$ & 9.0 & $4 \mathrm{NV}$ & LIGATION & Amputated \\
\hline 8 & 40 & $\mathrm{M}$ & RTA & PA & 7.0 & AV & $\mathrm{T}$ & Healing \& salvaged \\
\hline 9 & 18 & $\mathrm{M}$ & RTA & PA & 18.0 & $\mathrm{ND}$ & RSVG & Healing \& salvaged \\
\hline 10 & 33 & $\mathrm{M}$ & RTA & $\mathrm{PA}$ & 11.0 & AV & RSVG & Healing \& salvaged \\
\hline 11 & 58 & $\mathrm{M}$ & RTA & $\overline{P A}$ & 15.0 & $\mathrm{ND}$ & $T$ & Healing \& salvaged \\
\hline 12 & 47 & $\mathrm{M}$ & TG & $\mathrm{PA}$ & 8.0 & AV & $\mathrm{T}$ & Healing \& salvaged \\
\hline 13 & 42 & $\mathrm{M}$ & RTA & $\mathrm{PA}$ & 6.5 & AV & $\mathrm{EE}$ & Healing \& salvaged \\
\hline 14 & 36 & $F$ & RTA & $\mathrm{PA}$ & 17.0 & $1 \mathrm{NV}$ & $T$ & Healing \& salvaged \\
\hline 15 & 24 & $\mathrm{M}$ & RTA & $\mathrm{PA}$ & 3.0 & $\mathrm{ND}$ & RSVG & Healing \& salvaged \\
\hline 16 & 26 & $\mathrm{M}$ & TG & $\mathrm{PA}+\mathrm{PV}$ & 10.0 & $4 \mathrm{NV}$ & LIGATION & Amputated \\
\hline 17 & 42 & $\mathrm{M}$ & TG & $\mathrm{PA}$ & 6.0 & $\mathrm{ND}$ & RSVG & Healing \& salvaged \\
\hline 18 & 28 & $\mathrm{M}$ & $\mathrm{IG}$ & $\mathrm{PA}$ & 13.0 & $2 \mathrm{NV}$ & RSVG & Healing \& salvaged \\
\hline 19 & 27 & $F$ & IG & PA & 13.0 & $\mathrm{ND}$ & RSVG & Healing \& salvaged \\
\hline 20 & 37 & $\mathrm{M}$ & RTA & $\mathrm{PA}$ & 12.0 & AV & $\mathrm{VP}$ & Healing \& salvaged \\
\hline
\end{tabular}


Considering the long distances patients had to travel to get to the THA following PA injuries it is not surprising that ischemia times reaching 29 hours, median 9.5 hours, were well beyond the commonly taught 6 hour cut off. Immediate fasciotomy and an aggressive approach to revascularise and to deal with reperfusion whenever did pay off in the short term in not having to amputate in the perioperative period. Of course a long-term follow up is needed to establish if revascularizing severely damaged limbs is worthwhile.

Finally, four compartment fasciotomy at the primary hospital may have minimised ischaemic damage to skeletal muscle (8) during transfer of patients to THA. Unfortunately none of those treated at the THA had the benefit of a pre-transfer fasciotomy and it may be necessary to make fasciotomy a prerequisite in all instances where a patient with an extremity arterial injury is transferred.

All authors disclose no conflict of interest. The study was conducted in accordance with the ethical standards of the relevant institutional or national ethics committee and the Helsinki Declaration of 1975, as revised in 2000 .

\section{References}

1. Gopinathan NR, Santhanam SS, Saibaba B, et al. Epidemiology of lower limb musculoskeletal trauma with associated vascular injuries in a tertiary care institute in India. Indian J Orthop. 2017;51:199-204.

https://doi.org/10.4103/0019-5413.201702

2. Sciarretta JD, Macedo FI, Otero CA, et al. Management of traumatic popliteal vascular injuries in a level I trauma center: A 6-year experience. Int J Surg. 2015; 18: 136-141 https://doi.org/10.1016/j.ijsu.2015.04.056

3. Lang NW, Joestl JB, Platzer P. Charecteristics and clinical outcome in patients after popliteal artery injury. J Vasc Surg. 2015; 61(6): 1495-500. https://doi.org/10.1016/j.jvs.2015.01.045

4. Banderker MA, Navsaria P H, Edu S, et al. Civilian popliteal artery injuries. S Afr J Surg 2012;50(4):119-124 https://doi.org/10.7196/sajs.1257

5. Handagala DM, Gunasekara WD, Arulkumaran R. Trap-gun injuries--a menace in rural agricultural areas. Ceylon Med J. 2006 Dec;51(4):152 https://doi.org/10.4038/cmj.v51i4.1148

6. Moniz MP, Ombrellaro MP, Stevens SL, et al. Concomitant orthopedic and vascular injuries as predictors for limb loss in blunt lower extremity trauma. Am Surg. 1997 Jan;63(1):24-8

7. Dua A, Desai SS, Lee CJ. Amputation rate associated with revascularization procedure choice and injury type in popliteal artery, popliteal vein and concomitant popliteal artery and vein trauma. J Am Coll Surg.2014 Oct;219(4):e198-e199 https://doi.org/10.1016/j.jamcollsurg.2014.07.920

8. Farber A, Tan T, Hamburg NM, et al. Early fasciotomy in patients with extremity vascular injury is associated with decreased risk of adverse limb outcomes: A Review of the National Trauma Data Bank. Injury. 2012 Sep; 43(9): 1486-91 https://doi.org/10.1016/j.injury.2011.06.006 